\title{
Variation in morphology between core and marginal populations of three British damselflies ${ }^{1}$
}

\author{
Christopher Hassall, David J Thompson, and lan F Harvey
}

\begin{abstract}
As selective pressures are altered by the changing climate, species have been shown to shift their distributions. Here I investigate morphological variation in dispersal-related traits between core and marginal populations in three species of Odonata, a taxon that is known to be expanding polewards. I sampled individuals of (i) Calopteryx splendens, a species with a rapidly expanding range, (ii) Erythromma najas, a species with a slowly expanding range, and (iii) Pyrrhosoma nymphula, a species that does not exhibit a range margin in the UK (as a control). Only C. splendens exhibited consistent trends within two dispersal-related traits (wing:abdomen length ratio and aspect ratio). This result suggests that proximity to range margin alone does not account for variations in damselfly morphology, but that the rate of range expansion may also be important in determining variation.
\end{abstract}

\section{Introduction}

There is little doubt that global temperatures are increasing (Karl \& Trenberth, 2003) and predictions are that the rate of this warming will increase (Intergovernmental Panel on Climate Change (IPCC), 1996). A number of studies have documented the biological impacts that this climate change has had thus far (Parmesan \& Yohe, 2003, Walther et al., 2005). One of the best-documented results of increased environmental temperature is the shift in geographical distirbutions exhibited by a range of species (Hickling et al., 2006), supposedly caused by changes in the location of the fundamental niche.

Individual species shift their ranges through a complex combination of colonisations and extinctions (Holt \& Keitt, 2000). When the probability of colonisation and persistence is sufficiently high, new habitats can be colonised by individuals from within the existing range boundaries. However, the individuals that colonise new habitat patches are likely to be an unrepresentative sample of the population from which they disperse (Simberloff, 1981). It might be expected that individuals that found new colonies possess traits which increase the likelihood of successful dispersal. The progeny of those initial colonisers inherit those dispersal traits and make it more likely that subsequent colonisation will occur.

This scenario predicts a capacity for accelerating range expansion and has been demonstrated in the invasion of Australia by the cane toad, Bufo marinus (Amphibia), (Phillips et al., 2006) and in British Orthoptera (Thomas et al., 2001). Lepidoptera have also been shown to exhibit some enhanced dispersal-related traits at range margins compared to the core of ranges, including higher body mass, larger thoraces relative to total body mass and lower wing aspect ratios at recently colonised sites (Hill et al., 1999). Part of the adaptation to dispersal occurs not in exaggerating dispersal-related traits but in reducing traits that are not related to dispersal. In insects, the abdomen is largely reproductive in function and can constitute a significant proportion of the animal's mass. Reducing this mass results in a lower wing loading and, therefore, a greater capacity for dispersal.

The Odonata represent an order of insects which has recently been shown to be responding to climate change by advancing its phenology (Hassall et al., 2007, Dingemanse \& Kalkman, 2008) as well as expanding its range poleward in the UK (Hickling et al., 2005), elsewhere in Europe (Ott, 2007, Flenner \& Sahlén, 2008) and Japan (Aoki, 1997). This is not surprising given both the aerial

\footnotetext{
${ }^{1}$ The version of record can be viewed at the publisher and should be cited as Hassall, C., Thompson, D.J. and Harvey, I.F. (2009) Variation in morphology between core and marginal populations of three British damselflies. Aquatic Insects, 31 (3), 187-197.
} 
nature of its dispersal mechanism and the intimate links that the group has with temperature, including a tropical origin (Pritchard \& Leggott, 1987).

In this study I describe morphological variation pertaining to dispersal in three species of British damselfly with different range margin characteristics. Wing length is a reliable proxy for body size in damselflies (Cordero, 1994) as well as in insects in general (Southwood, 1968) and there is evidence that larger species disperse further than smaller species (Conrad et al., 1999). However, the absence of geometric similarity among species makes these comparisons equivocal (May, 1981). The biomechanics of odonate flight have been studied in detail (Rüppell, 1989, Wakeling \& Ellington, $1997 \mathrm{a}, \mathrm{b}, \mathrm{c}$ ) but this has rarely been related to the ecology of the species (Grabow \& Rüppell, 1995). Intraspecific studies of odonate flight morphology have focused on sexual selection and mating success and have not demonstrated variation in dispersal traits (Tsubaki \& Ono, 1987, Marden \& Waage, 1990). However, decreases in wing loading (or the related wing disk loading) are predicted to increase lift production (Marden, 1987) and high wing aspect ratio could provide greater massspecific lift at cold temperatures (Azevedo et al., 1998) and has been shown to correlate with greater flight speed in butterflies (Dudley \& Srygley, 1994).

I selected three candidate species to represent (i) an expanding range margin, (ii) a static range margin and (iii) variation on a similar latitudinal scale within a range. Using the British Dragonfly Society's database of sightings and the methods described in Hickling et al. (2005), I calculated the range shifts of all British Odonata over 18 time periods and found the mean annual shift for each species. I selected Calopteryx splendens (mean shift $=12.8 \mathrm{~km} \cdot \mathrm{yr}^{-1}$ ) as the expanding species, Erythromma najas (mean shift $=3.6 \mathrm{~km} \cdot \mathrm{yr}^{-1}$ ) as the slowly expanding species and Pyrrhosoma nymphula (mean shift $=1.3 \mathrm{~km}_{\text {. }} \mathrm{yr}^{-1}$ ). It is worth noting that $P$. nymphula has not expanded its range but that the apparent shift is a consequence of the methods used to calculate the range margin. I tested the hypothesis that the species exhibiting the most rapid expansion would possess the most exaggerated dispersal traits.

\section{Methods}

\section{Sampling}

Sites were selected to represent the core and margin of the three species' distributions in the UK (see Figure 1 and Table 1). The exception is $P$. nymphula, for which sites were chosen to give an equivalent latitudinal difference. Body size declines through the flight season (Banks \& Thompson, 1985 ) and so sites were visited over as short a space of time as possible to minimise this effect (Table 1). Phenology is retarded at higher latitudes and so sampling the northern sites after the southern sites partially accounted for this. Thirty males and thirty females were caught using a butterfly net from each pair of sites and kept in a coolbox until analysis.

\section{Measurements}

An attempt was made to sample the specimens non-destructively and so measurement of the specimens required anaesthesia. Chilling was selected for three reasons: (i) some studies have suggested that chilling is preferable to carbon dioxide anaesthesia (Barron, 2000), (ii) delivering consistent bouts of gaseous anaesthetic proved to be difficult and (iii) transporting nitrogen or carbon dioxide gas cylinders was not feasible.

As soon as possible after capture the individuals were removed from their bags and anaesthetised by chilling at approximately $-18^{\circ} \mathrm{C}$ using a $L e c$ U5006W tabletop freezer. The time required for adequate anaesthesia of each species varied and was determined during pilot studies. These times were 60 seconds for $P$. nymphula, 90 seconds for $E$. najas and 150 seconds for $C$. splendens.

Lateral and dorsal scans of all specimens were taken using a Canon Canoscan LiDE 25 flatbed scanner. Specimens were immobilised using microscope slides. The resulting images were 
analysed in ImageJ (Rasband, 1997-2007) to find the wing length and wing area of all four wings and abdominal length. Wing length was defined as the length from the costal end of the vein separating the arculus from the discoidal cell to the tip of the wing. It was not possible to take the area of the whole wing due to interference in the scan from the body, so the wing area excluded the portion defined by the junction of the first antenodal cross-vein and the costa, the margin of the arculus and across the anal crossing to the analis.

\section{Analysis}

The raw measurements were used to calculate two key dispersal traits: wing loading and aspect ratio. Since mass could not be measured accurately on live specimens, an index of flight ability was calculated using the ratio of right forewing length $(W L)$ to abdomen length $(A L)$. This index is similar to that used in studies on Drosophila and is inversely related to wing loading (Barker \& Krebs, 1995). Aspect ratio was calculated for both hind- and forewings as the square of the wingspan divided by the area. This was averaged across fore- and hindwings to give a mean aspect ratio.

A GLM was used to investigate variations between species, sites and sexes in body size (forewing length) and both of the dispersal traits. An interaction term of gender $\times$ site was added. Two-sample, two-tailed $t$-tests were used to test for differences between sites within each sex for each species. To account for the relatively large number of tests being performed (18 t-tests), a Bonferroni correction was applied by multiplying the $p$-values by the number of tests.

\section{Results}

GLMs showed that species, sex and site all exerted a significant effect on body size (Table 2). The site $\times$ sex interaction term was only significant in the case of body size, suggesting that males may increase in size to a greater extent than females at marginal populations. When differences between sites were considered, all species showed similar patterns of significantly greater size (as indicated by right forewing length) at the higher latitude site with the exception of E. najas females (Table 3, Figure 2). These relationships persisted after a Bonferroni correction for multiple tests.

The differences between sites in dispersal traits varied between species. In C. splendens, both males and females exhibited significantly higher aspect ratio at the northern site relative to the southern site (Table 3, Figure 3). In E. najas only the males possessed higher aspect ratio wings, with the trend in female aspect ratios becoming non-significant at the reduced $\alpha$-level. Neither $P$. nymphula males nor $P$. nymphula females exhibited a significant difference in aspect ratios between the two sites at the reduced $\alpha$-level.

The only significant difference between sites in WL:AL was found in $C$. splendens males, where those at the margin site possess a higher WL:AL ratio (Table 3, Figure 4). In both of the expanding species the direction of the effect was similar for each trait across all species and sexes.

\section{Discussion \\ Dispersal morphology}

Expanding ranges are predicted to lead to the development of exaggerated dispersal traits in marginal populations. The data presented here offer some support to that hypothesis. $C$. splendens, a species which is known to have expanded its range over the past 40 years, exhibits significantly higher aspect ratio at the northern range margin relative to a population closer to the core of the range.

Higher aspect ratio reduces drag and therefore promotes dispersal over larger distances (Vogel 1981). This trait also appears to vary in male $E$. najas although to a lesser extent than in $C$. splendens. This apparent continuum of response is emphasised by additional trends which were ruled out at a reduced a-level and adds support to our ranking of species as rapidly expanding, slowly expanding and static. A similar decrease in aspect ratio in response to increasing experimental 
temperature has been demonstrated in Drosophila melanogaster (Meigen 1830) (Azevedo et al. 1998).

Results from WL:AL data also seem to support the putative ranking of the three species in order of the magnitude of selective pressure on dispersal traits. The only groups to exhibit a significant difference in WL:AL were the male C. splendens. In an interspecific comparison of Calopteryx spp., southern species were shown to exhibit a lower wing loading (Grabow \& Rüppell, 1995). The same pattern of consistency in the direction of variation is present in WL:AL as in aspect ratio, with the two expanding species exhibiting higher WL:AL in the margin site but $P$. nymphula exhibiting weak and variable trends. The study by Azevedo et al. (1998) also showed that wing:thorax size ratio (a similar measure of wing loading to our WL:AL) decreased with increasing temperature, as seen in $C$. splendens males.

There are two potential components that may contribute to the observed variation in these two dispersal traits: phenotypic plasticity and adaptation. Drosophila melanogaster exhibits both plasticity to temperature and adaptation along a latitudinal transect in aspect ratio and wing:thorax size ratio (Azevedo et al., 1998). However, different populations of Drosophila subobscura (Diptera: Drosophilidae) have been shown to vary in their degree of local adaptation in terms of wing loading (wing area/thorax length) (Gilchrist \& Huey, 2004). In addition to temperature, wing morphology (length and width) in Calopteryx maculata was shown to vary between areas with different landscape structures (Taylor \& Merriam, 1995). Although an adaptive explanation is invoked for these observations, no attempt is made to partition the effects of plasticity and genetics.

Initial colonisers at a site benefit from an $r$-selected strategy to maximise fecundity in an environment that may be exhibiting greater fluctuations than core habitats (Zera \& Denno, 1997). However, increasing habitat persistence drives greater investment in reproduction, leading to benefits of a $K$ selected strategy. This mechanism may be responsible for the absence of difference between core and margin sites in $P$. nymphula. While it is not possible to rule out phenotypic plasticity to temperature, the difference in patterns of dispersal traits between $P$. nymphula and $C$. splendens suggests that the observed patterns are caused by more than simply a temperature effect.

The expansion of $E$. najas may be impaired by a close botanical association with certain floating plant species (including Nuphar lutea (Nymphaeaceae) (Hofmann \& Mason, 2005)). This hindrance could be the reason why such morphological patterns as those seen in $C$. splendens do not occur so strongly in this species. Habitat patches with the required botanical assemblage are too poorly connected to permit sufficient dispersal to generate a selective pressure towards enhanced dispersal traits. Indeed, the opposite could be true: in a fragmented landscape there may be a pressure towards reduced dispersal if dispersal entails a high probability of mortality (Travis \& Dytham, 1999).

\section{Morphology and range expansions}

Patterns of variation in body size tend to involve negative relationships with temperature and, therefore, positive correlations with increasing latitude such as those suggested by this study. However, while thermal and selective pressures may contribute to variation in body size, other factors have also been implicated in previous studies including prey density (Lawton et al., 1980) and photoperiod (De Block \& Stoks, 2003). Odonata are unique in apparently exhibiting a U-shaped relationship with temperature across the entire range (Johansson, 2003), comprising a classic temperature-size pattern at the poleward range margin, relatively little variation in the core of the range and then an inverse temperature-size relationship at the equatorward range margin. However, the same study did not investigate patterns of dispersal-related traits. There is some evidence that the size of British Odonata influences their dispersal ability (Conrad et al., 1999), a pattern that is seen across a wide range of taxa (Jenkins et al., 2007). Since available habitat is likely to be both patchy and ephemeral at range margins (Brown, 1984), a greater body size in marginal populations 
will facilitate colonisation of this lower connectivity landscape. It might be predicted from these assumptions that the lateral component of expansion into new habitats would be slow relative to the poleward dimension.

\section{Conclusions}

I have demonstrated evidence for an increase in dispersal ability at range margins compared to range cores. This result supports our initial hypothesis concerning the direction of trends in wing loading and aspect ratio and conforms to results found in studies in other taxa that are expanding their ranges (Hill et al., 1999, Phillips et al., 2006).

\section{References}

Aoki T (1997) Northward expansion of Ictinogomphus pertinax (Selys) in eastern Shikoku and western Kinki districts, Japan (Anisoptera: Gomphidae). Odonatologica, 26, 121-133.

Azevedo RBR, James AC, Mccabe J, Partridge L (1998) Latitudinal variation of wing:thorax size ratio and wing-aspect ratio in Drosophila melanogaster. Evolution, 52, 1353-1362.

Banks MJ, Thompson DJ (1985) Lifetime mating success in the damselfly Coenagrion puella. Animal Behaviour, 33, 1175-1183.

Barker JSF, Krebs RA (1995) Genetic variation and plasticity of thorax length and wing length in Drosophila aldrichi and D. buzzatii. Journal of Evolutionary Biology, 8, 689-709.

Barron AB (2000) Anaesthetising Drosophila for behavioural studies. Journal of Insect Physiology, 46, 439-442.

Brown JH (1984) On the relationship between abundance and distribution of species. The American Naturalist, 124, 255-279.

Conrad KF, Willson KH, Harvey IF, Thomas CJ, Sherratt TN (1999) Dispersal characteristics of seven odonate species in an agricultural landscape. Ecography, 22, 524-531.

Cordero A (1994) Reproductive allocation in different-sized adults Ischnura graellsii (Rambur) (Zygoptera: COenagrionidae). Odonatologica, 23, 271-276.

De Block M, Stoks R (2003) Adaptive sex-specific life history plasticity to temperature and photoperiod in a damselfly. Journal of Evolutionary Biology, 16, 986-995.

Dingemanse NJ, Kalkman VJ (2008) Changing temperature regimes have advanced the phenology of Odonata in the Netherlands. Ecological Entomology, 33, 394-402.

Dudley R, Srygley RB (1994) Flight physiology of neeotropical butterflies: allometry of airspeeds during natural free flight. Journal of Experimental Biology, 191, 125-139.

Flenner I, Sahlén G (2008) Dragonfly community reorganisation in boreal forest lakes: rapid species turnover driven by climate change? Insect Conservation and Diversity, 1, 169-179.

Gilchrist GW, Huey RB (2004) Plastic and genetic variation in wing loading as a function of temperature within and among parallel clines in Drosophila subobscura. Integrative and Comparative Biology, 44, 461-470.

Grabow K, Rüppell G (1995) Wing loading in relation to size and flight characteristics of European Odonata. Odonatologica, 24, 175-186.

Hassall C, Thompson DJ, French GC, Harvey IF (2007) Historical changes in the phenology of British Odonata are related to climate. Global Change Biology, 13, 933-941.

Hickling R, Roy DB, Hill JK, Fox R, Thomas CD (2006) The distributions of a wide range of taxonomic groups are expanding polewards. Global Change Biology, 12, 1-6.

Hickling R, Roy DB, Hill JK, Thomas CD (2005) A northward shift of range margins in British Odonata. Global Change Biology, 11, 502-506.

Hill JK, Thomas CD, Blakeley DS (1999) Evolution of flight morphology in a butterfly that has recently expanded its geographic range. Oecologia, 121, 165-170.

Hofmann TA, Mason CF (2005) Habitat characteristics and the distribution of Odonata in a lowland river catchment in eastern England. Hydrobiologia, 539, 137-147.

Holt RD, Keitt TH (2000) Alternative causes for range limits: a metapopulation perspective. Ecology Letters, 3, 41-47. 
Intergovernmental Panel on Climate Change (Ipcc) (1996) Climate Change 1995: The Science of Climate Change. Contribution of working group I to the second assessment report of the IPCC, New York, Cambridge University Press.

Jenkins DG, Brescacin CR, Duxbury CV et al. (2007) Does size matter for dispersal distance? Global Ecology and Biogeography, 16, 415.

Johansson F (2003) Latitudinal shifts in body size of Enallagma cyathigerum (Odonata). Journal of Biogeography, 30, 29-34.

Karl TR, Trenberth KE (2003) Modern global climate change. Science, 302, 1719-1723.

Lawton JH, Thompson BA, Thompson DJ (1980) The effects of prey density on survival and growth of damselfly larvae. Ecological Entomology, 5, 39-51.

Marden JH (1987) Maximum lift production during take-off in flying animals. Journal of Experimental Biology, 130, 235-258.

Marden JH, Waage JK (1990) Escalated damselfly contests are energetic wars of attrition. Animal Behaviour, 39, 954-959.

May ML (1981) Wingstroke frequency of dragonflies (Odonata: Anisoptera) in relation of temperature and body size. Journal of Comparative Physiology B-Biochemical Systemic and Environmental Physiology, 144, 229-240.

Ott $J$ (2007) The expansion of Crocothemis erythraea (Brullé, 1832) in Germany - an indicator of climatic changes. In: Odonata: Biology of dragonflies. (ed Tyagi BK) pp Page. Jodhpur, Scientific Publishers (India).

Parmesan C, Yohe G (2003) A globally coherent fingerprint of climate change impacts across natural systems. Nature, 421, 37-42.

Phillips BL, Brown GP, Webb JK, Shine R (2006) Invasion and the evolution of speed in toads. Nature, 439, 803.

Pritchard G, Leggott M (1987) Temperature, incubation rates and the origins of dragonflies. Advances in Odonatology, 3, 121-126.

Rasband WS (1997-2007) ImageJ. pp Page, National Institutes for Health, Bethesda, Maryland, USA, <http://rsb.info.nih.gov/ij/>.

Rüppell G (1989) Kinematic analysis of symmetrical flight manoeuvres of Odonata. Journal of Experimental Biology, 144, 13-42.

Simberloff D (1981) What makes a good island colonist? In: Insect life history patterns: habitat and geographic variation. (eds Denno RF, Dingle H) pp Page. New York, Springer.

Southwood TRE (1968) Ecological Methods (with particular reference to the study of insect populations), London, Methuen.

Taylor PD, Merriam G (1995) Wing morphology of a forest damselfly is related to landscape structure. Oikos, 73, 43-48.

Thomas CD, Bodsworth EJ, Wilson RJ, Simmons AD, Davies ZG, Musche M, Conradt L (2001) Ecological and evolutionary processes at expanding range margins. Nature, 411, 577-581.

Travis JMJ, Dytham C (1999) Habitat persistence, habitat availability and the evolution of dispersal. Proceedings of the Royal Society: Series B (Biological Sciences), 266, 723-728.

Tsubaki Y, Ono T (1987) Effects of age and body size on the male territorial system of the dragonfly, Nannophya pygmaea Rambur (Odonata: Libellulidae). Animal Behaviour, 35, 518-525.

Wakeling JM, Ellington CP (1997a) Dragonfly flight. II. Velocities, accelerations and kinematics of flapping flight. Journal of Experimental Biology, 200, 557-582.

Wakeling JM, Ellington CP (1997b) Dragonfly flight. III. Lift and power requirements. Journal of Experimental Biology, 200, 583-600.

Wakeling JM, Ellington CP (1997c) Dragonfly flight: I Gliding flight and steady-state aerodynamic forces. Journal of Experimental Biology, 200, 543-556.

Walther GR, Berger S, Sykes MT (2005) An ecological "footprint" of climate change. Proceedings of the Royal Society: Series B (Biological Sciences), 272, 1427-1432.

Zera AJ, Denno RF (1997) Physiology and ecology of dispersal polymorphism in insects. Annual Review of Entomology, 42, 207-230. 
Table 1 - Locations of sampling sites and ordinal dates (days since $1^{\text {st }}$ January) on which they were sampled.

\begin{tabular}{llccccc}
\hline & \multicolumn{3}{c}{ Core sites } & \multicolumn{3}{c}{ Marginal sites } \\
\cline { 2 - 7 } Species & Latitude & Longitude & Sampling date & Latitude & Longitude & Sampling date \\
\hline C. splendens & $51.356^{\circ} \mathrm{N}$ & $0.888^{\circ} \mathrm{W}$ & $175-179$ & $55.092^{\circ} \mathrm{N}$ & $1.704^{\circ} \mathrm{W}$ & $185-187$ \\
E. najas & $51.330^{\circ} \mathrm{N}$ & $0.822^{\circ} \mathrm{W}$ & $166-174$ & $53.214^{\circ} \mathrm{N}$ & $2.594^{\circ} \mathrm{W}$ & $178-181$ \\
P. nymphula & $50.957^{\circ} \mathrm{N}$ & $0.978^{\circ} \mathrm{W}$ & $176-179$ & $56.734^{\circ} \mathrm{N}$ & $3.023^{\circ} \mathrm{W}$ & $190-191$ \\
\hline
\end{tabular}


Table 2 - Results of GLM of species, sex and site as factors explaining variation in three morphological traits.

\begin{tabular}{llll}
\hline & Body size & WL:AL & Aspect ratio \\
\hline Species & $F_{2,403}=7579(p<0.001)$ & $F_{2,402}=1301(p<0.001)$ & $F_{2,370}=2285(p<0.001)$ \\
Sex & $F_{1,403}=545.0(p<0.001)$ & $F_{1,402}=920.6(p=0.007)$ & $F_{1,370}=222.7(p<0.001)$ \\
Site & $F_{1,370}=173.5(p<0.001)$ & $F_{1,402}=6.520(p=0.011)$ & $F_{1,370}=58.88(p<0.001)$ \\
Sex $\times$ Site & $F_{1,370}=9.850(p=0.002)$ & $F_{1,402}=0.560(p=0.456)$ & $F_{1,370}=2.420(p=0.121)$ \\
\hline
\end{tabular}


Table 3 - Pairwise comparison of morphology at core and margin sites in three damselfly species. p-values are multiplied by 18 to control for multiple tests. ${ }^{a}=$ right forewing length, ${ }^{b}$ $=$ right forewing length/abdominal length, ${ }^{\mathrm{c}}=$ wingspan/wing area ${ }^{2}$ averaged across fore- and hindwings.

\begin{tabular}{llllr}
\hline Trait & Species & Sex & \multicolumn{2}{l}{$l$} \\
\hline Body size $^{\mathrm{a}}$ & C. splendens & Male & $\mathbf{8 . 5 5}$ & $<\mathbf{0 . 0 0 1}$ \\
& & Female & $\mathbf{7 . 9 9}$ & $<\mathbf{0 . 0 0 1}$ \\
& E. najas & Male & $\mathbf{3 . 9 0}$ & $\mathbf{0 . 0 0 5}$ \\
& & Female & 2.18 & 0.594 \\
& P. nymphula & Male & $\mathbf{4 . 0 8}$ & $\mathbf{0 . 0 0 2}$ \\
& & Female & $\mathbf{1 1 . 9 6}$ & $<\mathbf{0 . 0 0 1}$ \\
\hline WL/AL $^{\mathrm{b}}$ & C. splendens & Male & $\mathbf{3 . 7 7}$ & $\mathbf{0 . 0 0 6}$ \\
& & Female & 1.72 & 1.602 \\
& \multirow{2}{*}{ E. najas } & Male & 0.56 & 10.350 \\
& & Female & 1.59 & 2.124 \\
& P. nymphula & Male & -1.19 & 4.284 \\
& & Female & 0.89 & 6.750 \\
\hline Aspect ratio $^{c}$ & C. splendens & Male & $\mathbf{7 . 6 9}$ & $<\mathbf{0 . 0 0 1}$ \\
& & Female & $\mathbf{6 . 4 4}$ & $<\mathbf{0 . 0 0 1}$ \\
& \multirow{2}{*}{ E. najas } & Male & $\mathbf{3 . 3 2}$ & $\mathbf{0 . 0 3 6}$ \\
& & Female & 2.95 & 0.090 \\
& P. nymphula & Male & 2.40 & 0.360 \\
& & Female & -0.24 & 14.562 \\
\hline
\end{tabular}




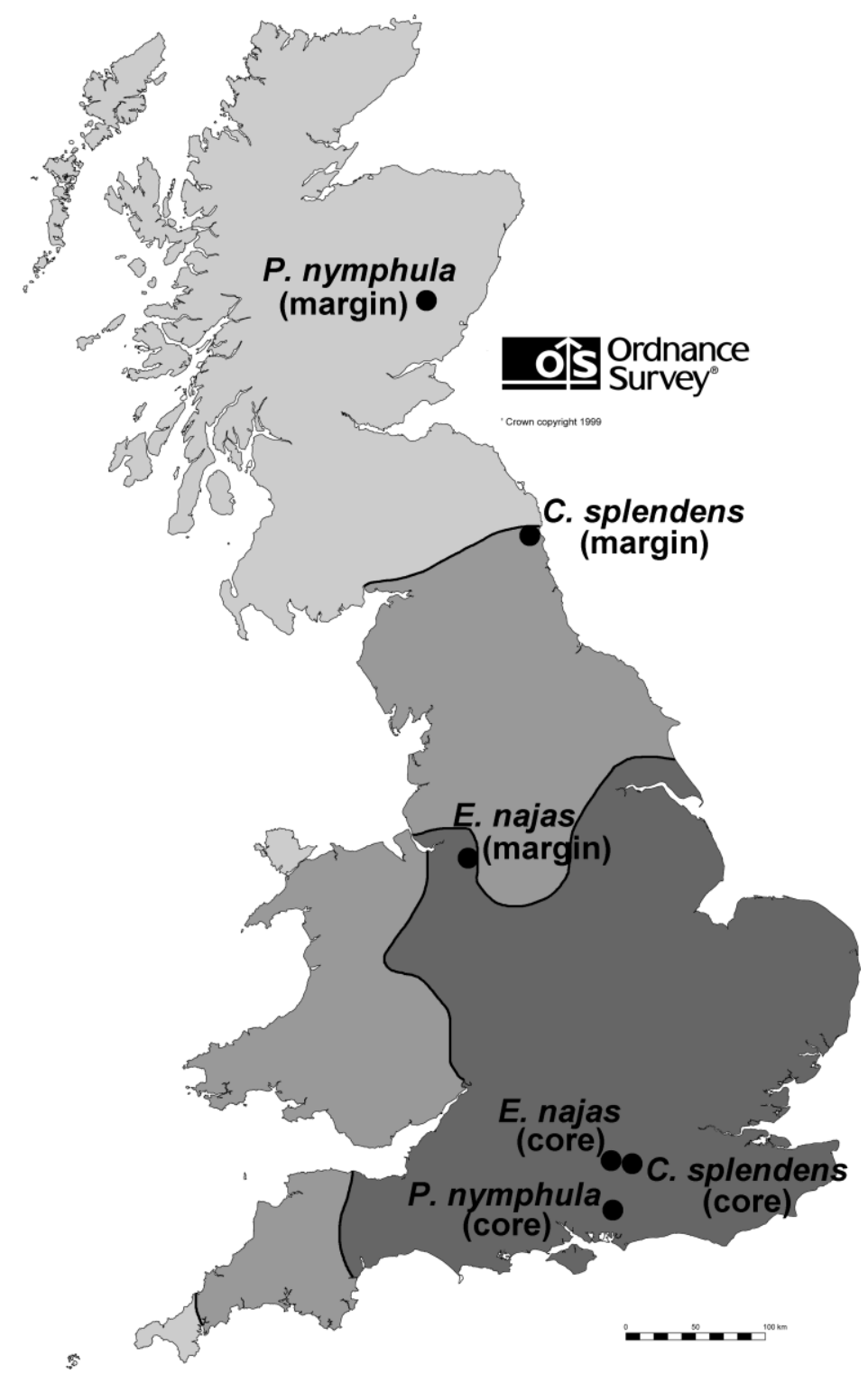

Figure 1 - Map showing locations of core and margin sampling sites in relation to the ranges of the three species. Ranges are concentric such that the range of Calopteryx splendens encompasses that of Erythromma najas and Pyrrhosoma nymphula encompasses both of the other species. Dark grey shows range of $E$. najas, middle grey shows range of $C$. splendens and light grey shows range of $P$. nymphula. 


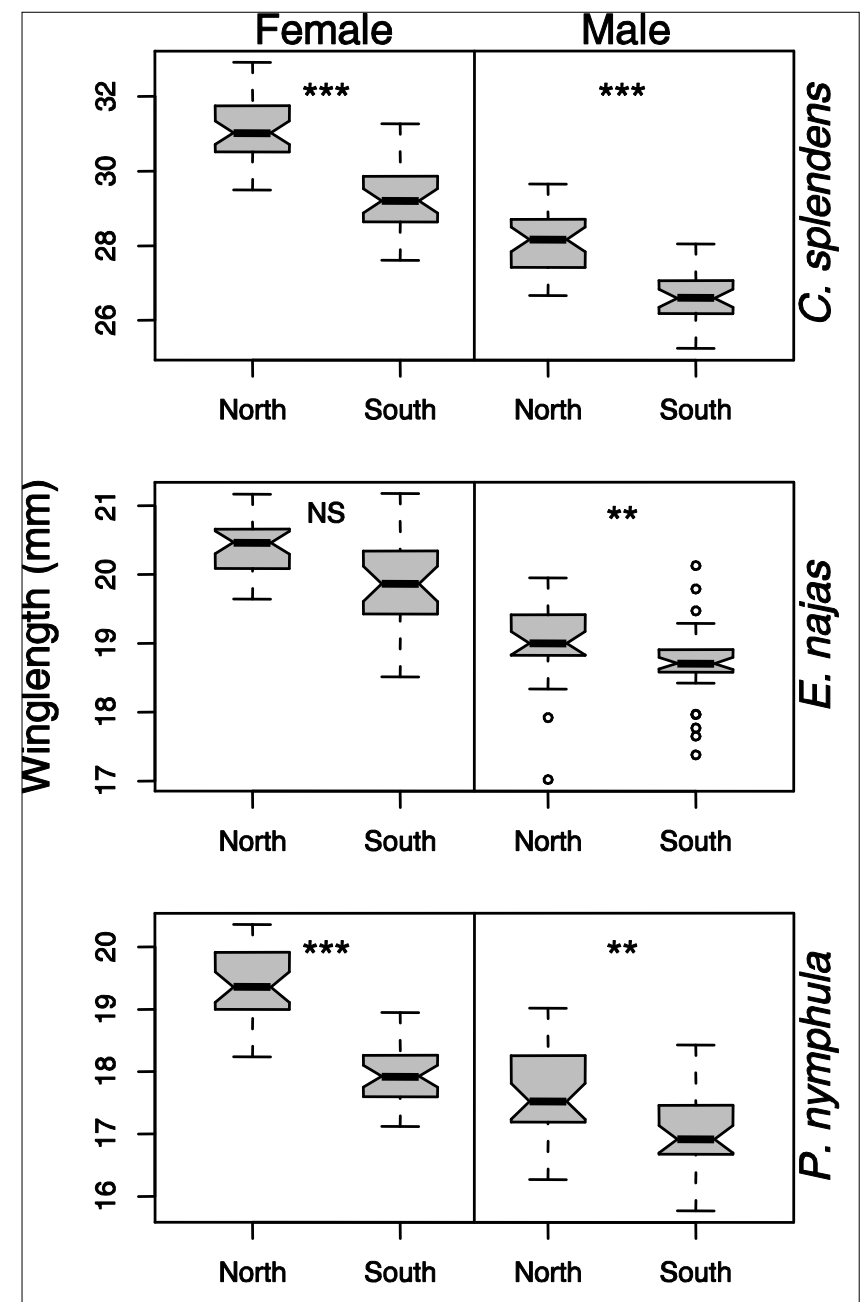

Figure 2 - Variation in body size (as indicated by length of the right forewing (RFW)) between species, sexes and sites. NS $=p>0.05,{ }^{*}=p<0.05,{ }^{* *}=p<0.01,{ }^{* * *}=p<0.001$. $p$-values include Bonferroni correction for multiple tests. 


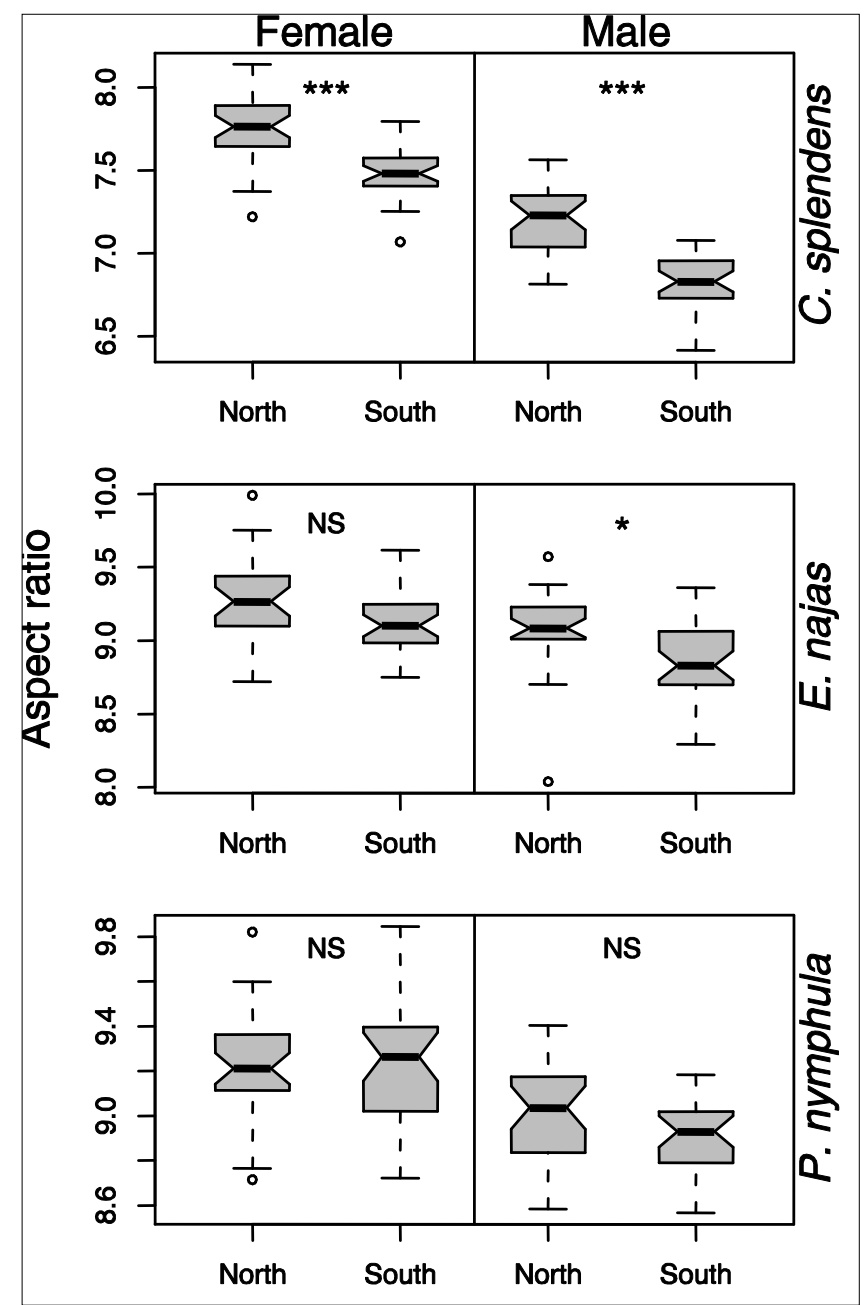

Figure 3 - Variation in aspect ratio between sites for both sexes of each species. NS $=p>0.05$, ${ }^{*}=p<0.05,{ }^{* *}=p<0.01,{ }^{* * *}=p<0.001$. $p$-values include Bonferroni correction for multiple tests. 


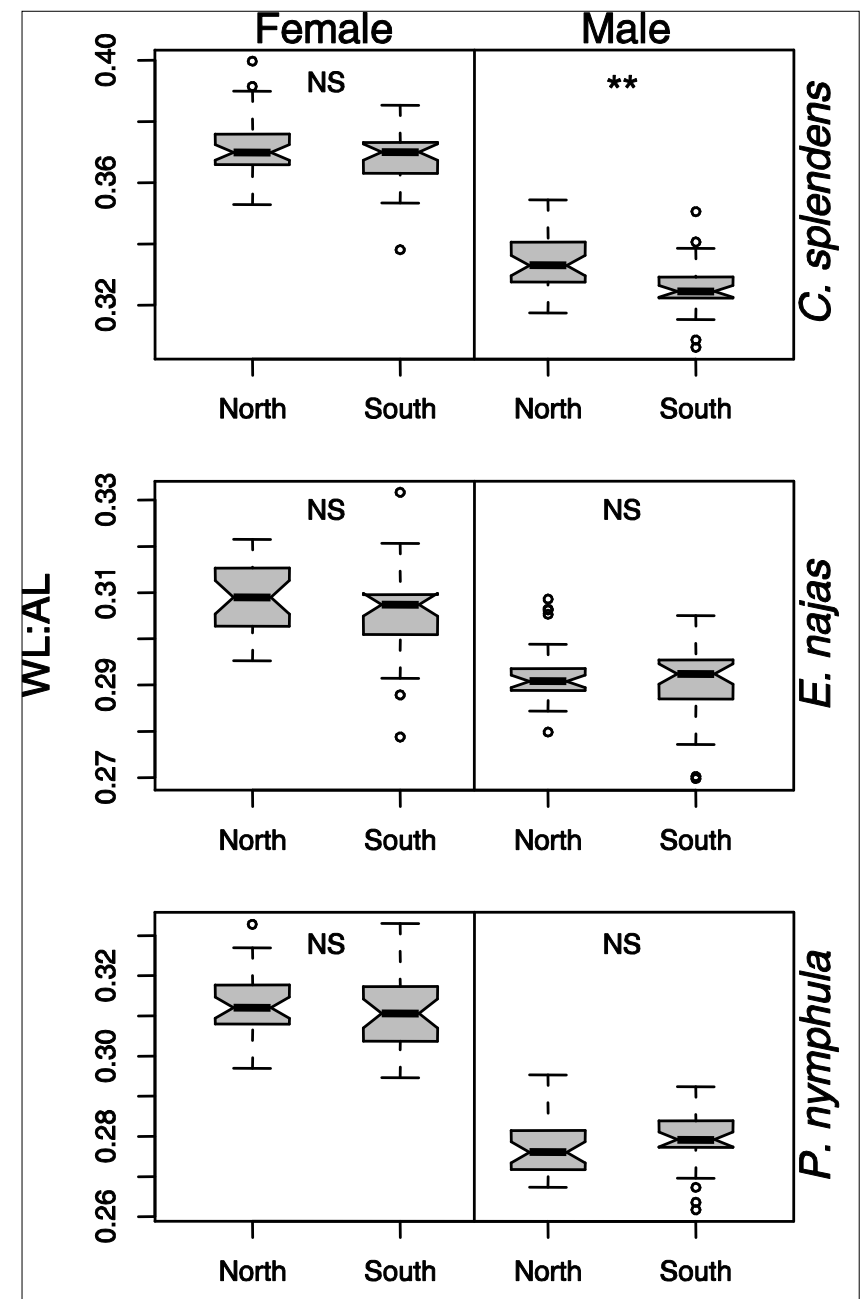

Figure 4 - Variation in WL:AL (wing length : abdomen length) ratio between sites for both sexes of each species. NS $=p>0.05,{ }^{*}=p<0.05,{ }^{* *}=p<0.01,{ }^{* * *}=p<0.001$. $p$-values include Bonferroni correction for multiple tests. 